http://ejtr.vumk.eu

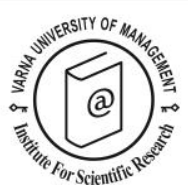

\title{
Volunteer Tourism: A Path to Buen Vivir?
}

\author{
Steven Owen ${ }^{1}$
}

Received: 11/03/2019

\begin{abstract}
${ }^{1}$ University of St Andrews, Irvine Building, North Street, KY16 9AL, Scotland, UK. Tel: 07834688633 . E-mail: So31@st-andrews.ac.uk

Coordinating editor: Faizan Ali
\end{abstract}

Supervisors: Prof Nina Laurie and Dr Sharon Leahy

Institution awarding the Ph. D. Degree: University of St Andrews

Date of defence: 01/05/2018

Citation: Owen, S. (2019) Volunteer Tourism: A Path to Buen Vivir? Doctoral Dissertation Summary. European Journal of Tourism Research 23, pp. 217-220

\section{Goal and objectives of the dissertation}

The popularity of volunteer tourism stems from its discursive positioning as fostering mutually beneficial relations between volunteer tourists and the host destination. Despite extensive scholarly work, the outcomes of this activity for host communities and volunteer tourists are still unclear. This thesis provides new insights by providing an alternative reading of this tourism practice. It achieves this in two important ways. Firstly, it analyses volunteer tourism through the indigenous knowledge system of Buen Vivir thereby challenging endemic practices of relying on frameworks originating from the Global North. Secondly, it incorporates the diverse voices of host community members, who have tended to be excluded from volunteer tourism studies. The thesis has the following Aim and Research Questions:
Aim

To critically assess volunteer tourism in Ecuador using the lens of Buen Vivir.

\section{Research Questions}

1 How is Buen Vivir discursively constructed at the national level in Ecuador, and how does this relate to tourism development in the country?

2 How is an indigenous community in Ecuador constructed as a site for volunteer tourism?

3 How do different indigenous members interpret volunteer tourism, and what factors shape this interpretation?

4 How do volunteer tourists interpret their experience in the indigenous communities?

\section{Methodology}

This thesis takes a qualitative ethnographic approach from a social constructivist

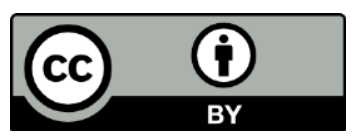

This work is licensed under the Creative Commons Attribution 4.0 International (CC BY 4.0). To view a copy of this license, visit https://creativecommons.org/licenses/by/4.0/ 
perspective. It is based on a four and half month study in two indigenous communities in Ecuador - one Kichwa community in the town of Chilcapamba and one Tsa'chila community near the town of Santa Domingo. It incorporates a range of stakeholders including indigenous host members, volunteer tourists and NGO representatives, gathering data through the use of semi-structured interviews, focus groups, participant observation and a field diary. In addition, it draws on two months of document analysis conducted on 70 on-line documents, including Ecuadorian policy statements, News Broadcasters and travel publications.

\section{Results}

The results indicate that the Ecuadorian state discursively associates tourism with the concept of Buen Vivir, positioning tourism as a mechanism to achieve small scale and harmonious development. However, it employs practices typical of the neo-liberal agenda, focusing on creating an optimal business environment for the expansion of the tourism industry. Therefore, in spite of its discursive positioning, the Ecuadorian state is ambivalent to Buen Vivir, utilising its discourses, but adopting policies fitting with neo-liberal development models. Narrowing to the community level, the results indicate that in becoming a site for volunteer tourism a 'volunteer space' is created in the host communities. This space is co-constructed through an on-going process of negotiations between indigenous hosts, NGO and volunteers, reflecting their own priorities for engaging in this tourism practice. The result is a volunteer space, where the physical environment and self-performance of indigenous members is moulded to create a successful product for the volunteer tourism market. The volunteer space takes the form of a 'simulacrum' to satisfy Western imaginaries of an indigenous community, whilst countering negative imaginaries, which are traditionally propagated within Ecuadorian society. Similarly, the volunteer tourists occupying this space self-manage their performance to conform to a desired volunteer identity. This limits the opportunity for an unconstrained cross-cultural encounter between volunteer tourist and host, or for the volunteer tourists' preconceptions or understandings to be challenged in any significant way. Moreover, in creating the volunteer space, knowledge and practices from the Global North are prioritised, whilst locally embedded knowledge are delegitimised. As a result, the elite in the community, who are most adaptable to this knowledge, secure greatest involvement and financial reward from the volunteer tourism projects. Conversely, community members less-adaptable to this knowledge are marginalised, exacerbating existing inequalities within the indigenous communities. The results show that those members involved in the projects, justify rewards as reflecting them being entrepreneurial and taking advantage of emergent opportunities, whilst those marginalised mobilise the discourses of Buen Vivir to resist the practices employed in the volunteer tourism projects.

\section{Theoretical conclusions}

This thesis contributes to theoretical understanding by illustrating how volunteer tourism embodies the spirit of neo-liberal development models under way in countries of the Global South. It contends that, in spite of volunteer tourism's discursive positioning as an alternative tourism practice, it functions through and reinforces the structures and imaginaries of an unequal and uneven global economic system. This is because, whilst volunteer tourism flows across global boundaries as an apolitical practice, on establishing itself in communities of the Global South, it draws these communities into the global tourism industry. This results in the prioritisation of knowledge and practices from the Global North, which valorises individual autonomy and responsibility, over collective practices based on solidarity and reciprocity. However, the thesis demonstrates the discourses of Buen Vivir are an important mechanism by which marginalised indigenous members can challenge and unsettle these hegemonic discourses originating from the Global North, and adopted by local elites. This illustrates how Global South frameworks provide an important departure point for 
understanding how volunteer tourism materialises in relation to locally embedded knowledge and practices. Moreover, the thesis contributes to theoretical understanding of the 'volunteer tourist', by demonstrating their neo-liberal subjectivity in how they selfmanage and narrate their experience in communities of the Global South.

\section{Practical application of the dissertation}

The thesis argues that in spite of its discursive positioning volunteer tourism projects operate in a similar manner to alternative development initiatives. As a result, to increase the potential of more equitable outcomes, greater consideration needs to be given to how best practice operates in these models. As a priority, volunteer tourism projects should ensure they operate in a way which is transparent, democratic and inclusive of local knowledge. Moreover, it is essential that there is long term engagement, with the aim of empowering and building the capacities of the most marginalised community members, so that they can become active agents in the volunteer tourism projects. The thesis identifies and acknowledges the difficulty in achieving this on-the-ground in communities of the Global South. It therefore begins the discussion of how volunteer tourism can go beyond the 'spectacle' of development, to be considered a viable development strategy in communities of the Global South. In addition, the thesis calls for volunteer tourism projects to incorporate a critical pedagogy, to empower volunteer tourists to reflect on their experience in the host community in new ways. This should actively include host community members from diverse socioeconomic backgrounds, facilitating understanding beyond 'disneyfied' and homogenous representations, to one reflective of an indigenous community as dynamic, heterogeneous, and stratified. Moreover, this critical pedagogy should empower volunteer tourists to think beyond individual action, to one that encourages collective engagement with the deeper structural causes of poverty and inequality.

\section{Content of the dissertation}

Abstract of Chapter 1
Chapter One outlines how the author's initial understanding of volunteer tourism was unsettled during the thesis, and the journey to re-conceptualising this tourism practice through the alternative worldview of Buen Vivir.

\section{Abstract of Chapter 2}

Chapter Two analyses the genealogy of the literatures relating to development and volunteer tourism, tracing their shifting patterns. It concludes with a conceptual framework, illustrating how current understanding of volunteer tourism and development sit within the academic literature, whilst also pointing to avenues to be explored in the empirical chapters.

\section{Abstract of Chapter 3 \\ Chapter Three provides an explanation of the methodology employed in the thesis. It outlines the epistemological and ontological stance adopted, as well as the data collection methods utilised. The decisions made throughout the thesis are justified in relation to theoretical arguments and practical considerations.}

\section{Abstract of Chapter 4 \\ Chapter Four contextualises the study by tracing the genealogy of Buen Vivir and tourism at the national level in Ecuador. It argues that the Ecuadorian state has both enshrined Buen Vivir as a national political objective, and designated tourism as an important mechanism for its realisation. The chapter proposes that despite utilising the discourses of Buen Vivir, the Ecuadorian state employs practices typical of the neo- liberal agenda.}

\section{Abstract of Chapter 5 \\ Chapter Five analyses the processes and negotiations which occur when an indigenous community becomes a site for volunteer tourism. It argues that volunteer tourism incorporates indigenous communities into the global tourism industry, thereby transforming it from a place of residence into a commercial volunteer space. It argues that this volunteer space is a simulacrum, an indigenous community that never existed beyond western imaginaries.}




\begin{abstract}
Chapter 6
Chapter Six offers an analysis of indigenous members' participation and interpretation of volunteer tourism within their community. Framed within the context of forms of capital, specifically social, financial, cultural and human capital, the chapter illustrates the likelihood of community members' involvement in volunteer tourism projects. It then brings to the fore the different cultural sets, which influence indigenous members' interpretation of volunteer tourism in their community. It shows that individuals involved in the project frame volunteer tourism practices according to neo-liberal discourses. Conversely, indigenous members excluded from the volunteer tourism projects critique its practices through the discourses of Buen Vivir.
\end{abstract}

\section{Abstract of Chapter 7}

Chapter Seven deconstructs the volunteer tourists' identities within the indigenous communities studied. It argues that volunteer tourists have a fluid, ambivalent identity, through their role as both volunteer and tourist. It identifies specific moments in which this ambivalent state dissolves, and when a clear volunteer or tourist identity is acknowledged. This chapter subsequently argues that volunteer tourists strategically manage and narrate their experience in the indigenous communities to achieve desirable outcomes.

\section{Abstract of Chapter 8}

Chapter Eight takes stock of the major arguments of this thesis, namely that volunteer tourism embodies the spirit of neoliberal development models, whilst Buen Vivir provides a critical avenue for unsettling this agenda, by providing a framework through which alternative possibilities can be imagined. The chapter reinforces the thesis contribution to the existing literature, and points to possible avenues of future research. 